\title{
Asymptomatic Plasmodium infections in 18 villages of southern Savannakhet Province, Lao PDR (Laos)
}

\author{
Koukeo Phommasone ${ }^{1 \dagger}$, Bipin Adhikari ${ }^{2 \dagger}$, Gisela Henriques ${ }^{2}$, Tiengkham Pongvongsa ${ }^{3}$, Panom Phongmany ${ }^{3}$, \\ Lorenz von Seidlein ${ }^{2,4^{*}}$, Nicholas J. White ${ }^{2,4}$, Nicholas P. J. Day ${ }^{2,4}$, Arjen M. Dondorp ${ }^{2,4}$, Paul N. Newton 1,4, \\ Mallika Imwong ${ }^{2}$ and Mayfong Mayxay ${ }^{1,4,5}$
}

\begin{abstract}
Background: A large fraction of Plasmodium infections do not cause clinical signs and symptoms of disease and persist at densities in blood that are not detectable by microscopy or rapid diagnostic tests. These infections may be critical as a transmission reservoir in areas of low malaria endemicity. Understanding the epidemiology of these infections would be helpful for malaria elimination.

Methods: A cross-sectional survey was conducted in Thapangthong and Nong Districts of Savannakhet Province, Lao PDR, to determine the prevalence of parasitaemia. A total of 888 blood samples were collected from afebrile volunteers aged $\geq 15$ years in 18 villages during March and July 2015. Plasmodium infections were diagnosed by rapid diagnostic tests (RDT) and high volume, ultra-sensitive quantitative polymerase chain reaction (UPCR).

Results: UPCR detected Plasmodium infections in 175 of 888 samples (20\%). The species distribution was Plasmodium falciparum $3.6 \%$ (32/888), Plasmodium vivax $11.1 \%$ (99/888), mixed infections with P. falciparum and P. vivax $1.6 \%$ (14/888) and Plasmodium of undetermined species $3.4 \%$ (30/888). RDT identified only $2 \%$ (18/888) positive cases. Using UPCR as reference, the sensitivity and specificity of RDTs were 28 and $100 \%$, respectively, in detecting $P$. falciparum infections, and 3 and $99 \%$ in detecting asymptomatic P. vivax infections. The K13 kelch propeller domain C580Y mutation, associated with reduced susceptibility to artemisinin derivatives, was found in $75 \%(12 / 18)$ of $P$. falciparum isolates from Thapangthong and in $7 \%(2 / 28)$ from Nong $(p<0.001)$. In a multivariate analysis, males were more likely to have P. vivax infections [adjusted odds ratio (aOR) $4.76(95 \% \mathrm{Cl} 2.84-8.00)$ ] while older villagers were at lower risk for parasitaemia [aOR for increasing age 0.98 (95 \% Cl 0.96-0.99)].

Conclusion: There is a high prevalence of asymptomatic Plasmodium infections in southern Savannakhet. Artemisinin-resistant P. falciparum strains form an increasing proportion of the parasite population in Thapangthong District and are already present in the more remote Nong District. This worrying trend has wider implications for Laos and could reverse the gains achieved by the successful control of malaria in Laos and the Greater Mekong Sub-region (GMS). Rapid elimination of P. falciparum has to be a top priority in Laos as well as in the wider GMS.
\end{abstract}

Keywords: Asymptomatic, RDT, uPCR, Prevalence, Lao PDR

\footnotetext{
*Correspondence: Lorenz@tropmedres.ac

${ }^{\dagger}$ Koukeo Phommasone and Bipin Adhikari contributed equally to this

work

${ }^{2}$ Mahidol Oxford Tropical Medicine Research Unit (MORU), Faculty

of Tropical Medicine, Mahidol University, Bangkok, Thailand

Full list of author information is available at the end of the article
} 


\section{Background}

Substantial progress has been made in the control of malaria in the Lao PDR (Laos), in particular in the north of the country. The five southernmost provinces, Savannakhet, Salavan, Sekong, Champasack, and Attapeu accounted for $90 \%$ of all malaria patients reported in the country in 2008 [1]. A nationwide malaria survey conducted between 2006 and 2008, including 495 health centres in Savannakhet Province, reported an overall incidence of 11.5 Plasmodium falciparum cases per 1000 people. The survey ranked Savannakhet as the province with the third highest $P$. falciparum cases recorded in 2008 [2].

In Laos, many remote health centres rely on rapid diagnostic tests (RDT) for malaria diagnosis. Few regional and district-level health centres have access to microscopy [3]. The nationwide prevalence survey carried out during 2006-2008 was based on passive case reporting by provincial and district hospitals, provincial malaria stations, health centres, and village health workers (VHWs). Case detection was based on either RDTs or microscopy $[1,2]$. The majority of malaria infections remained undetected since only symptomatic cases were captured [4-7]. People with asymptomatic Plasmodium infections can carry very low parasite densities, for extended periods, which are undetectable by microscopy or RDTs $[5,6]$. Mosquitoes feeding on blood samples from individuals with sub-microscopic Plasmodium infections can become infected $[8,9]$. Thus, sub-microscopic carriers contribute to malaria transmission $[10,11]$.

The elimination of malaria in the greater Mekong Subregion (GMS) has become particularly urgent with the emergence and spread of artemisinin resistance, the failure of artemisinin combination therapy (ACT) partner drugs, and the threat of untreatable malaria [12]. Current recommendations to prevent further spread of drugresistant malaria from Southeast Asia advocate regional malaria elimination $[13,14]$. As a part of National Strategic Plan for Malaria Control and Elimination 2011-2015, Laos has adopted the goal of eliminating malaria by 2030 $[1,15]$.

To gain a better understanding of which villages need to be targeted for malaria elimination, a survey was conducted in 18 villages of southern Savannakhet Province, which has a historically high malaria prevalence based on village malaria worker records.

\section{Methods}

\section{Study site and design}

The study was conducted in southern Savannakhet Province, Laos. The province is $\sim 600 \mathrm{~km}$ south from Vientiane, the capital city of Laos. It has a total area of $21,774 \mathrm{~km}^{2}$ and includes 15 districts [16]. Savannakhet is the most populous province of Laos with a total population of $\sim 843,245$ people, representing about $14 \%$ of the population of the country. The province has one provincial hospital, 15 district hospitals and 115 health centres. This health system covers approximately $89 \%$ of the province's geographical area [17]. Cross-sectional surveys were conducted in Thapangthong and Nong Districts (see Fig. 1). The districts and villages were chosen based on the previous high malaria incidence in provincial epidemiological records. Villagers were informed by local health centre staff of the reasons for the survey and requested to arrive at a suitable location within each village. A mobile study team with blood collection equipment, tools for anthropometry and essential medicines conducted the study in each village.

\section{Study participants and procedures}

A description of the study was announced at village meetings. Additional explanations about the study were provided to each participant during the consent process before blood sample collection. Volunteers of age $\geq 15$ years were enrolled into the study. Written consent was obtained from each volunteer before participation. Travel costs were reimbursed and vitamin B complex and/or haematinics were given to the study participants based on the judgment of study clinicians. Information on demographics (age, sex, weight, height), tympanic temperature, history of fever and history of illness during the previous $48 \mathrm{~h}$, a history of malaria, anti-malarial drug treatment, recent travel, and bed net use was collected using the Open Data Kit $\left(\mathrm{ODK}^{\circledR}\right)$ application on a smartphone.

\section{Sample collection}

Villagers who met the inclusion criteria were asked to give $3 \mathrm{~mL}$ venous blood samples which were collected into EDTA tubes and stored in ice pack cooling boxes until their transportation to a centralized field laboratory in the two districts (within $6 \mathrm{~h}$ of blood collection). Upon return to the centralized laboratory, the whole blood was separated and the red blood cell pellets were frozen promptly and stored at $-20{ }^{\circ} \mathrm{C}$ for up to 7 days. Each sample was labelled with a barcode to ensure blinding and negative controls were added to the sample pool. The samples were transported on dry ice to the molecular parasitology laboratory in Bangkok, Thailand for analysis.

All participants were tested on site for malaria using the SD Bioline Ag Pf/Pan (Standard Diagnostics Inc) RDT. Those with positive RDTs were treated with artemether/lumefantrine, as per Laos national treatment guidelines. The RDT test was performed and interpreted by an experienced laboratory technician according to manufacturer's recommendation. 

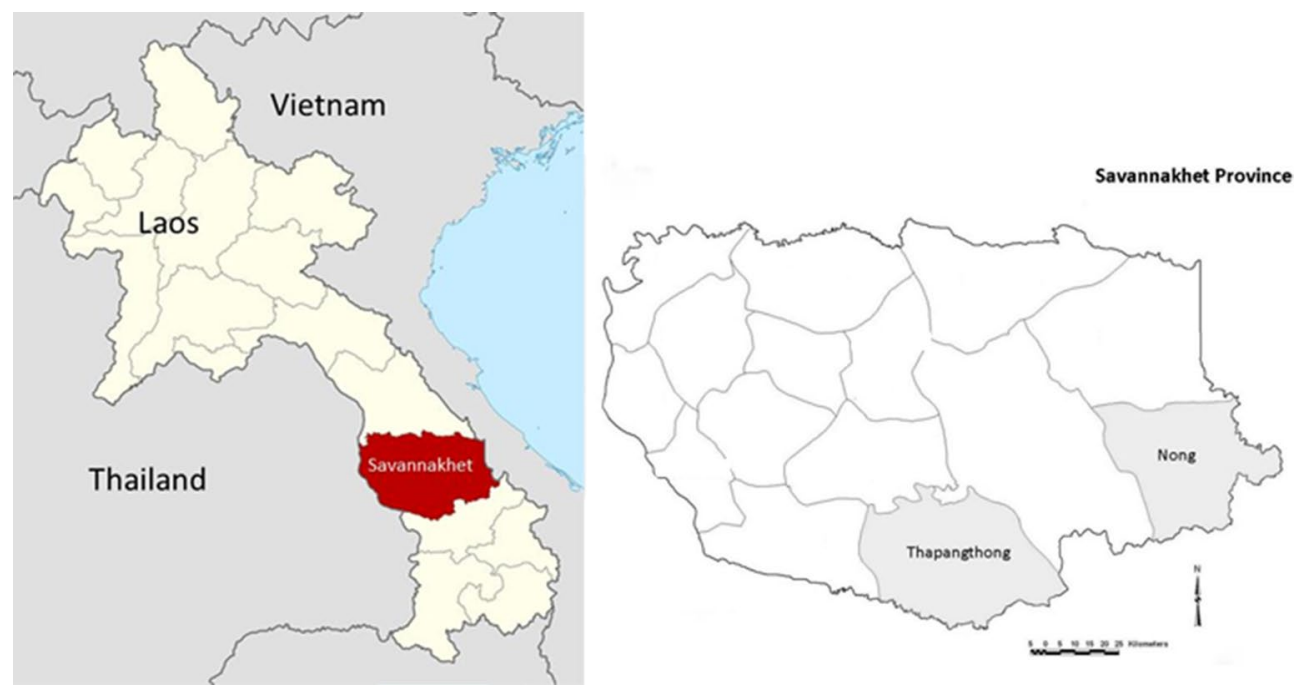

Fig. 1 Study sites within Savannakhet Province

\section{DNA extraction and PCR amplification}

DNA was extracted from thawed packed red blood cells using an automated DNA extraction machine (QIAsymphony and DPS DNA midi kit; Qiagen, Germany). DNA was dried, concentrated and then used as a template for PCR detection and quantification of Plasmodium. Quantitative ultrasensitive PCR ( $\mathrm{UPCR}$ ) analysis was performed as described elsewhere [18]. Briefly, DNA of Plasmodium was detected and quantified using $18 \mathrm{~S}$ rRNA-targeting primers. The limit of detection was $\sim 22$ parasites $/ \mathrm{mL}$. For Plasmodium-positive samples, an attempt was made to identify the species using $P$. falciparum- and Plasmodium vivax-specific PCR protocols as described previously [18].

To detect polymorphisms associated with reduced susceptibility to artemisinin derivatives, the open-reading frame of the PF3D7_1343700 kelch propeller domain was amplified using a nested PCR protocol $[12,19]$. Purified PCR products were sequenced at Macrogen, Republic of Korea, and analysed using BioEdit version 7.1.3.0., using the 3D7 kelch13 sequence as reference (Accession: XM_001350122.1). The definition of single nucleotide polymorphisms (SNPs) was based on analytical approaches described previously $[12,20]$.

\section{Statistical analysis}

Asymptomatic malaria was defined as a Plasmodium infection detected in study participants who were afebrile (tympanic temperature of $<37.5{ }^{\circ} \mathrm{C}$ ) at the time of the survey and had no history of fever in the preceding $48 \mathrm{~h}$. Sub-microscopic infections were here defined as a Plasmodium infection with densities too low to be detectable by microscopy and malaria RDT but detectable by uPCR.

Descriptive statistics were used to analyse the baseline characteristics of the study population. The Chi squared test and Kruskal-Wallis test were used to test associations between variables and Plasmodium infection in univariate analyses. Multiple logistic regression models were constructed and used to explore associations between $P$. falciparum mono-infections and independent co-variables as well as for $P$. vivax mono-infections and independent co-variables. Variables which were significant at the $\mathrm{P}<0.05$ level in the univariate analysis were evaluated in a multivariable regression model. The models were run for any Plasmodium infections and then for $P$. falciparum and $P$. vivax as dependent variables. $P$ values less than 0.05 were considered statistically significant. Statistical analysis was performed using STATA 14.0 (StataCorp, College Station, TX, USA).

\section{Ethics statement}

Ethical approval for the study was received from the Lao National Ethics Committee for Health Research (Ref No 013-2015/NECHR), Government of the Laos and the Oxford Tropical Research Ethics Committee (1015-13). Individual informed consent was obtained from each participant.

\section{Results}

A total of 888 volunteers, 433 from eight villages in Thapangthong District and 455 from ten villages in Nong District participated in the study. The surveys were conducted between 21 and 24 March, 2015 in Thapangthong 
District and between 22 and 26 July, 2015 in Nong District.

\section{Demographic characteristics of participants}

The overall median age was 33 years (IQR 22-47 years). More than half (57\%) of the participants were in the age range between 15 and 35 years and 479/888 (54\%) were male. Only two among 888 participants $(0.2 \%)$ had a fever $\left(\geq 37.5^{\circ} \mathrm{C}\right)$ at the time of the survey (Table 1). One febrile participant $\left(39.3^{\circ} \mathrm{C}\right)$ was blood smear- and RDT-negative but was later found to be infected by $P$. vivax using uPCR. The other participant $\left(37.6{ }^{\circ} \mathrm{C}\right)$ was not parasitaemic. The mean weight and height of participants were $48 \mathrm{~kg}$ $(\mathrm{SD}=7.6)$ and $153 \mathrm{~cm}(\mathrm{SD}=7.3)$, respectively.

\section{Prevalence of Plasmodium infections}

Overall, Plasmodium parasites were detected in 175/888 individuals $(20 \%)$ by uPCR (Table 2): 99/888 (11 \%) had $P$. vivax mono-infections, 32/888 (4\%) had $P$. falciparum mono-infections and 14/888 (2\%) had mixed

Table 1 Baseline characteristics of the study population $(n=888)$

\begin{tabular}{|c|c|c|c|c|c|c|}
\hline \multirow[t]{3}{*}{ Characteristics } & \multicolumn{5}{|l|}{ Results } & \multirow[t]{3}{*}{ P value ${ }^{* *}$} \\
\hline & \multirow[t]{2}{*}{ Negative } & \multicolumn{4}{|l|}{ Positive } & \\
\hline & & P. falciparum & P. vivax & Mixed $(P f+P v)^{a}$ & Plasmodium spp. & \\
\hline \multicolumn{7}{|l|}{ Sex } \\
\hline Male $(n=479)$ & $354(74 \%)$ & $16(3 \%)$ & $76(16 \%)$ & $10(2 \%)$ & $23(5 \%)$ & \multirow[t]{2}{*}{$<0.001$} \\
\hline Female $(n=409)$ & $359(88 \%)$ & $16(4 \%)$ & $23(6 \%)$ & $4(1 \%)$ & $7(2 \%)$ & \\
\hline \multicolumn{7}{|l|}{ Age group } \\
\hline $15-35$ years $(n=505)$ & $383(76 \%)$ & $22(4 \%)$ & $73(15 \%)$ & $8(2 \%)$ & $19(4 \%)$ & \multirow[t]{3}{*}{0.009} \\
\hline $36-55$ years $(n=234)$ & $196(84 \%)$ & 7 (3 \%) & $20(9 \%)$ & $5(2 \%)$ & $6(3 \%)$ & \\
\hline $56-80$ years $(n=149)$ & $134(90 \%)$ & $3(2 \%)$ & $6(4 \%)$ & $1(0.7 \%)$ & $5(3 \%)$ & \\
\hline Mean age in years $(n=888 ; S D)$ & $37.0(16.2)$ & $32.0(13.9)$ & $30.9(13.6)$ & $32.9(13.9)$ & $34.7(15.7)$ & 0.005 \\
\hline \multicolumn{7}{|l|}{ History of Fever in the last $48 \mathrm{~h}$} \\
\hline Yes $(n=277)$ & $223(80 \%)$ & $17(6 \%)$ & $26(9 \%)$ & $4(1 \%)$ & $7(3 \%)$ & \multirow[t]{2}{*}{0.056} \\
\hline No $(n=611)$ & $490(80 \%)$ & $15(3 \%)$ & $73(12 \%)$ & $10(2 \%)$ & $23(4 \%)$ & \\
\hline \multicolumn{7}{|l|}{ Feeling ill in the last $48 \mathrm{~h}$} \\
\hline Yes $(n=451)$ & $370(82 \%)$ & $20(4 \%)$ & $43(10 \%)$ & $5(1 \%)$ & $13(3 \%)$ & \multirow[t]{2}{*}{0.186} \\
\hline No $(n=437)$ & $343(79 \%)$ & $12(3 \%)$ & $56(13 \%)$ & $9(2 \%)$ & $17(4 \%)$ & \\
\hline \multicolumn{7}{|l|}{ History of malaria } \\
\hline Yes $(n=493)$ & $367(74 \%)$ & $21(4 \%)$ & $76(15 \%)$ & $10(2 \%)$ & $19(4 \%)$ & \multirow[t]{2}{*}{$<0.001$} \\
\hline No $(n=385)$ & $336(87 \%)$ & $11(3 \%)$ & $23(6 \%)$ & $4(1 \%)$ & $11(3 \%)$ & \\
\hline \multicolumn{7}{|l|}{ Episodes of malaria } \\
\hline 0 Episodes $(n=395)$ & $346(88 \%)$ & $11(3 \%)$ & $23(6 \%)$ & $4(1 \%)$ & $11(3 \%)$ & \multirow[t]{3}{*}{$<0.001$} \\
\hline $1-3$ episodes $(n=409)$ & $320(78 \%)$ & $20(5 \%)$ & $47(12 \%)$ & $7(2 \%)$ & $15(4 \%)$ & \\
\hline$>3$ episodes $(n=84)$ & $47(56 \%)$ & $1(1 \%)$ & $29(35 \%)$ & $3(4 \%)$ & $4(5 \%)$ & \\
\hline \multicolumn{7}{|c|}{ Stay overnight in the forest in the last 3 months $^{\text {a }}$} \\
\hline$<2$ weeks ago $(n=183)$ & $136(74 \%)$ & $7(4 \%)$ & $30(16 \%)$ & $3(2 \%)$ & $7(4 \%)$ & \multirow[t]{4}{*}{$<0.001$} \\
\hline $2-4$ weeks ago $(n=27)$ & $16(59 \%)$ & $1(4 \%)$ & $8(30 \%)$ & $1(4 \%)$ & $1(4 \%)$ & \\
\hline$>4$ weeks ago $(n=66)$ & $43(65 \%)$ & $1(2 \%)$ & $15(23 \%)$ & $4(6 \%)$ & $3(5 \%)$ & \\
\hline No forest visits $(n=612)$ & $518(85 \%)$ & $23(4 \%)$ & $46(8 \%)$ & $6(1 \%)$ & $19(3 \%)$ & \\
\hline \multicolumn{7}{|c|}{ Travelled outside the village in the last 3 months ${ }^{a}$} \\
\hline Yes $(n=232)$ & $188(81 \%)$ & $10(4 \%)$ & $23(10 \%)$ & $4(2 \%)$ & $7(3 \%)$ & \\
\hline No $(n=656)$ & $525(80 \%)$ & $22(3 \%)$ & $76(12 \%)$ & $10(2 \%)$ & $23(4 \%)$ & 0.902 \\
\hline \multicolumn{7}{|l|}{ Bed net use } \\
\hline Every day ( $n=682)$ & $559(82 \%)$ & $26(4 \%)$ & $67(10 \%)$ & $8(1 \%)$ & $22(3 \%)$ & \multirow[t]{3}{*}{0.132} \\
\hline Sometimes $(n=143)$ & $108(76 \%)$ & $3(2 \%)$ & $24(17 \%)$ & $4(3 \%)$ & $4(3 \%)$ & \\
\hline Never $(n=63)$ & $46(73 \%)$ & $3(5 \%)$ & $8(13 \%)$ & $2(3 \%)$ & $4(6 \%)$ & \\
\hline
\end{tabular}

${ }^{a}$ Mixed infection with P.falciparum and $P$. vivax

** Chi squared test 
infections (P. vivax and $P$. falciparum). The Plasmodium species could not be determined in specimens from $30 / 888$ (3.4 \%) patients. The prevalence of $P$. vivax monoinfections was significantly lower in Nong [5 \% (22/455)] than in Thapangthong [18\% (77/433); $\mathrm{p}<0.0001]$. In contrast, the prevalence of $P$. falciparum mono-infections was higher in Nong [5\% (24/455)] compared to Thapangthong [2 \% (8/433); $\mathrm{p}=0.1$; Table 2]. There was also high variability in Plasmodium prevalence within districts. In the eight villages in Thapangthong District the Plasmodium infection prevalence ranged between 12 and $39 \%$ and in the ten villages in Nong District between 4 and $56 \%$.

\section{Resistance markers}

The mutation C580Y in the PF3D7_1343700 kelch propeller domain, which is associated with reduced susceptibility to artemisinin derivatives, was found in $32 \%$ (of 14/44) P. falciparum strains (Table 2). No other kelch polymorphisms were detected. The C580Y mutation was found in $75 \%(12 / 18)$ of $P$. falciparum strains detected in
Thapangthong and in $7 \%(2 / 28)$ strains detected in Nong $(\mathrm{p}<0.001)$.

\section{Plasmodium prevalence by RDT}

RDTs detected eight participants $(8 / 888 ; 0.9 \%)$ with $P$. falciparum mono-infections, six participants (6/888; $0.7 \%)$ with non-P. falciparum infections and four participants $(4 / 888 ; 0.5 \%)$ with mixed infections ( $P$. falciparum and non-P. falciparum; Table 3). Using uPCR as reference, the sensitivity and specificity of RDTs were 28 and $100 \%$, respectively, in detecting P. falciparum infections and 3 and $99 \%$ in detecting $P$. vivax infections (Table 4).

\section{Factors associated with Plasmodium infections}

Five covariates were independently and significantly associated with $P$. vivax mono-infections (Table 5): male sex [Odds Ratio adjusted for age and district 4.76 (95\% CI 2.84-8.00)], increasing age [aOR 0.98 (95\% CI 0.96-0.99)], residing in Nong District [aOR 0.16 (95\% CI $0.10-0.27)$ ], a history of three or more

Table 2 Parasite prevalence detected by uPCR by village and district $(n=888)$

\begin{tabular}{|c|c|c|c|c|c|c|}
\hline \multirow[t]{2}{*}{ Villages } & \multirow[t]{2}{*}{ Negative } & \multicolumn{4}{|l|}{ Positive } & \multirow{2}{*}{$\begin{array}{l}\text { PfK-13 resistance } \\
\text { Marker C580Y }\end{array}$} \\
\hline & & $P F$ & $P F+P V$ & $P V$ & P species & \\
\hline \multicolumn{7}{|l|}{ Thapangthong District } \\
\hline Maiphosy $(n=50)$ & $38(76 \%)$ & 0 & $1(2 \%)$ & $11(22 \%)$ & 0 & 1/1 (100 \%) \\
\hline Bouttaphan $(n=59)$ & $42(71 \%)$ & $1(2 \%)$ & $2(3 \%)$ & $14(24 \%)$ & 0 & $3 / 3(100 \%)$ \\
\hline Maixe $(n=58)$ & $47(81 \%)$ & $2(3 \%)$ & 0 & $7(12 \%)$ & $2(3 \%)$ & $1 / 2(50 \%)$ \\
\hline Phouphanang $(n=56)$ & $37(66 \%)$ & $2(4 \%)$ & $1(2 \%)$ & $15(27 \%)$ & $1(2 \%)$ & $3 / 3(100 \%)$ \\
\hline Phoumaly $(n=52)$ & $42(81 \%)$ & $1(2 \%)$ & $1(2 \%)$ & $6(12 \%)$ & $2(4 \%)$ & $2 / 2(100 \%)$ \\
\hline Nalao $(\mathrm{n}=52)$ & $40(77 \%)$ & $1(2 \%)$ & $2(4 \%)$ & $7(13 \%)$ & $2(4 \%)$ & $0 / 3$ \\
\hline Khampia (n = 49) & $30(61 \%)$ & $1(2 \%)$ & $1(2 \%)$ & $14(29 \%)$ & $3(6 \%)$ & $2 / 2(100 \%)$ \\
\hline Kengkhai $(n=57)$ & $50(88 \%)$ & 0 & 0 & $3(5 \%)$ & $4(7 \%)$ & $0 / 0$ \\
\hline Thapangthong Total $(n=433)$ & $326(75 \%)$ & $8(2 \%)$ & $8(2 \%)$ & $77(18 \%)$ & $14(3 \%)$ & $12 / 16(75 \%)$ \\
\hline \multicolumn{7}{|l|}{ Nong District } \\
\hline Oi Tan Tip $(n=50)$ & $22(44 \%)$ & $4(8 \%)$ & $5(10 \%)$ & $15(30 \%)$ & $4(8 \%)$ & $0 / 8$ \\
\hline Denvilay $(n=50)$ & $46(92 \%)$ & $1(2 \%)$ & 0 & $2(4 \%)$ & $1(2 \%)$ & $0 / 1$ \\
\hline Asing na $(n=19)$ & $15(79 \%)$ & $1(5 \%)$ & 0 & $2(11 \%)$ & $1(5 \%)$ & $0 / 1$ \\
\hline Asing saly $(n=29)$ & $27(93 \%)$ & 0 & 0 & 0 & $2(7 \%)$ & $0 / 0$ \\
\hline Phounmakmy $(n=57)$ & $46(81 \%)$ & $9(16 \%)$ & 0 & 0 & $2(4 \%)$ & $0 / 8$ \\
\hline Kaysone $(n=50)$ & $46(92 \%)$ & $2(4 \%)$ & 0 & $1(2 \%)$ & $1(2 \%)$ & $0 / 1$ \\
\hline Thathe $(n=49)$ & $45(92 \%)$ & $1(2 \%)$ & $1(2 \%)$ & $1(2 \%)$ & $1(2 \%)$ & $1 / 2(50 \%)$ \\
\hline Xuangtai $(n=50)$ & $44(88 \%)$ & $3(6 \%)$ & 0 & 0 & $3(6 \%)$ & $0 / 1$ \\
\hline Paloy $(n=47)$ & $45(96 \%)$ & $1(2 \%)$ & 0 & $1(2 \%)$ & 0 & $1 / 1(100 \%)$ \\
\hline Salang $(n=54)$ & $51(94 \%)$ & $2(4 \%)$ & 0 & 0 & $1(2 \%)$ & $0 / 2$ \\
\hline Nong Total $(n=455)$ & $387(85 \%)$ & $24(5 \%)$ & $6(1 \%)$ & $22(5 \%)$ & $16(4 \%)$ & $2 / 28(7 \%)$ \\
\hline Overall Total $(n=888)$ & $713(80 \%)$ & $32(4 \%)$ & $14(2 \%)$ & $99(11 \%)$ & $30(3 \%)$ & $14 / 44$ (32\%) \\
\hline
\end{tabular}


Table 3 Plasmodium species identification by RDT and qPCR

\begin{tabular}{|c|c|c|c|c|c|c|}
\hline \multirow[t]{2}{*}{ RDT } & \multicolumn{6}{|l|}{ qPCR } \\
\hline & Negative & P. falciparum & P. vivax & Mixed $^{a}$ & Plasmodium spp. & Total \\
\hline Negative & 708 & 23 & 96 & 13 & 30 & 870 \\
\hline P. falciparum & 0 & 7 & 0 & 1 & 0 & 8 \\
\hline Non-falciparum & 4 & 0 & 2 & 0 & 0 & 6 \\
\hline Mixed infection ${ }^{a}$ & 1 & 2 & 1 & 0 & 0 & 4 \\
\hline Total & 713 & 32 & 99 & 14 & 30 & 888 \\
\hline
\end{tabular}

${ }^{a}$ P. falciparum and $P$. vivax

Table 4 RDT performance characteristics (sensitivity, specificity, positive predictive value, negative predictive value)

\begin{tabular}{llllll}
\hline \multicolumn{1}{c}{ RDT } & & \\
\cline { 3 - 5 } & Sensitivity \% $\mathbf{9 5} \% \mathbf{~ C l})$ & Specificity \% (95 \% Cl) & PPV (95 \% Cl) & NPV (95 \% Cl) \\
\hline UPCR & P. falciparum $(n=36)$ & $27.8(14.2-45.2)$ & $99.9(99.1-100)$ & $90.9(57.1-99.5)$ & $96.5(94.8-97.6)$ \\
& P. vivax $(n=109)$ & $2.7(0.7-8.2)$ & $99.3(98.3-99.7)$ & $37.5(10.2-74.1)$ & $86.7(84.1-88.9)$ \\
\hline
\end{tabular}

$P P V$ positive predictive value, $N P V$ negative predictive value

Table 5 Multiple logistic regression analysis to identify independently significant variables associated with $P$. vivax mono-infections ( $\mathrm{n}=99$ )

\begin{tabular}{|c|c|c|c|c|}
\hline Covariates & $\begin{array}{l}\text { Univariate analysis } \\
\text { Crude OR ( } 95 \% \mathrm{Cl})\end{array}$ & P value & $\begin{array}{l}\text { Multivariate analysis } \\
\text { Adj. OR }(95 \% \mathrm{Cl})\end{array}$ & $P$ value \\
\hline Sex male $(n=812)$ & $3.35(2.06-5.46)$ & $<0.001$ & $4.76(2.84-8.00)^{a}$ & $<0.001$ \\
\hline Age $(n=812)$ & $0.97(0.96-0.99)$ & 0.001 & $0.98(0.96-0.99)^{b}$ & 0.002 \\
\hline District Nong $(\mathrm{n}=812)$ & $0.21(0.13-0.34)$ & $<0.001$ & $0.16(0.10-0.27)^{c}$ & $<0.001$ \\
\hline History of Fever in the previous $48 \mathrm{~h}(\mathrm{n}=812)$ & $0.78(0.49-1.26)$ & 0.31 & $1.02(0.61-1.72)^{d}$ & 0.92 \\
\hline Feeling ill in the previous $48 \mathrm{~h}(\mathrm{n}=812)$ & $0.71(0.47-1.09)$ & 0.12 & $0.98(0.62-1.55)^{d}$ & 0.92 \\
\hline History of 3 or more malaria episodes $(n=802)$ & $9.28(4.96-17.36)$ & $<0.001$ & $1.56(1.08-2.25)^{d}$ & 0.02 \\
\hline Stay overnight in the forest in the last 3 months $(n=812)$ & $3.06(2.00-4.70)$ & $<0.001$ & $2.45(1.17-5.11)^{d}$ & 0.02 \\
\hline Travelled outside the village in the last 3 months $(n=812)$ & $0.85(0.51-1.39)$ & 0.50 & $0.92(0.54-1.57)^{d}$ & 0.76 \\
\hline Bed net never used $(n=812)$ & $1.28(0.58-2.79)$ & 0.31 & $1.55(0.66-3.66)^{d}$ & 0.45 \\
\hline
\end{tabular}

adjusted for age and district

b adjusted for sex and district

c adjusted for age and sex

$\mathrm{d}$ adjusted for age, sex and district

malaria episodes [aOR 1.56 (95\% CI 1.08-2.25)], and an overnight stay in a forest in the last 3 months [aOR 2.45 (95\% CI 1.17-5.11)]. There was a statistically significant association between a history of fever in the previous $48 \mathrm{~h}$ and $P$. falciparum mono-infections [aOR 2.47 (95\% CI 1.20-5.08; Table 6)]. Increasing age was found to be protective against $P$. falciparum infection in the univariate analysis [OR 0.97 (95\% CI $0.96-1.00)$ ] but not in the multivariate analysis [aOR $0.98(0.95-1.00)]$.

\section{Discussion}

This is the first survey conducted in Laos of sub-clinical and sub-microscopic Plasmodium infections using uPCR. The study found that one-fifth of the afebrile population in southern Savannakhet was carrying Plasmodium infections, a third of which $P$. falciparum infections may be resistant to artemisinin derivatives. The prevalence of asymptomatic Plasmodium infection was very heterogeneously distributed not only between districts but also between villages separated by short distances. 
Table 6 Multiple logistic regression analysis to identify independently significant variables associated with $P$. falciparum mono-infections $(n=32)$

\begin{tabular}{|c|c|c|c|c|}
\hline Covariates & $\begin{array}{l}\text { Univariate analysis } \\
\text { Crude OR }(95 \% \mathrm{Cl})\end{array}$ & $P$ value & $\begin{array}{l}\text { Multivariate analysis } \\
\text { OR adj. (95\% Cl) }\end{array}$ & $P$ value \\
\hline Sex male $(n=745)$ & $1.01(0.50-2.06)$ & 0.97 & $0.84(0.87-4.65)^{\mathrm{a}}$ & 0.65 \\
\hline Age $(n=745)$ & $0.97(0.96-1.00)$ & 0.01 & $0.98(0.95-1.00)^{b}$ & 0.08 \\
\hline District Nong $(n=745)$ & $1.89(0.84-4.3)$ & 0.12 & $2.02(0.87-4.65)^{c}$ & 0.10 \\
\hline History fever in the last $48 \mathrm{~h}(\mathrm{n}=745)$ & $2.49(1.22-5.08)$ & 0.01 & $2.47(1.20-5.08)^{d}$ & 0.01 \\
\hline Feeling ill in the last $48 \mathrm{~h}(\mathrm{n}=745)$ & $1.55(0.74-3.21)$ & 0.24 & $1.70(0.81-3.59)^{d}$ & 0.16 \\
\hline History of any malaria $(n=735)$ & $1.75(0.83-3.68)$ & 0.14 & $1.68(0.79-3.61)^{d}$ & 0.18 \\
\hline History of 3 or more malaria episodes $(n=735)$ & $0.67(0.09-5.30)$ & 0.70 & $0.87(0.10-7.40)^{d}$ & 0.90 \\
\hline Stay overnight in the forest in the previous 3 months $(n=745)$ & $1.04(0.47-2.28)$ & 0.92 & $1.04(0.44-2.41)^{d}$ & 0.94 \\
\hline Travelled outside the village in the previous 3 months $(n=745)$ & $1.27(0.59-2.73)$ & 0.54 & $1.91(0.55-2.58)^{d}$ & 0.66 \\
\hline Bed net never used $(n=745)$ & $1.50(0.44-5.11)$ & 0.52 & $1.18(0.34-4.10)^{d}$ & 0.80 \\
\hline
\end{tabular}

a adjusted for age and district

b adjusted for sex and district

c adjusted for age and sex

d adjusted for age, sex and district

There has been a shift from the traditional dominance of $P$. falciparum, which used to be the most prevalent $(\geq 90 \%)$ species in Laos, towards P. vivax [21-25]. An increase in the proportion of $P$. vivax infections has been reported from Thailand [26], Cambodia [27], Solomon Islands [28], Amazon [29, 30], and Central America [31] as falciparum malaria incidence has declined. A recent, large, multi-centre, cross-sectional survey conducted in Cambodia, Vietnam and Thai-Myanmar border found almost twice as many $P$. vivax infections compared to $P$. falciparum infections among a total of 988 Plasmodium infections [32]. Current malaria control practices in Laos are more effective in the control of $P$. falciparum than $P$. vivax. The complete, radical cure of vivax infections requires a 14-day course with 8 -aminoquinolines, such as primaquine, and this is not implemented currently. There remains considerable reluctance to use primaquine in radical cure while G6PD testing is unavailable and there is therefore a significant haemolytic risk.

A high geographical heterogeneity was also found in the distribution of the $\mathrm{K} 13$ mutation $\mathrm{C} 580 \mathrm{Y}$ which is associated with resistance against artemisinin derivatives [12, 19]. In Thapangthong District $75 \%$ of the tested P. falciparum strains had the K13 C580Y mutation. In contrast, in Nong District the K13 mutation was only detected in $7 \%$ of $P$. falciparum strains. This finding supports the hypothesis that with decreasing falciparum malaria transmission the more resistant strains replace wild type strains infections form an increasing proportion of the dwindling parasite population [14].

The heterogeneity in the prevalence of Plasmodium infections may at least in part be explained by environmental factors, such as the location of homes in relation to mosquito breeding sites, the design and construction materials of the home, and protective measures taken by the residents. The heterogeneity in the prevalence of Plasmodium infections in this study is consistent with an earlier study conducted in Laos [2]. The reason for heterogeneity suggested by the authors included the proximity of deep forest and the characteristics of the principal vectors in Laos which are Anopheles dirus and Anopheles minimus [33]. The dispersal range of $A n$. dirus and An. minimus, combined with the anthropophilic behaviour of $A n$. minimus was thought to explain at least some of the variability in malaria prevalence between villages [33, 34]. In a study conducted in Cambodia, villages proximal to forested areas had a higher prevalence of Plasmodium infections compared to villages more distant from forested areas [35]. Detailed observations on the micro-epidemiology of $P$. falciparum infections found similar large differences between villages in sub-Saharan Africa and in Europe in the last century [36]. Different environmental (mosquito densities, abundance of larval habitats) and human-mosquito behaviour (exposure to mosquitoes due to occupation, such as working in the forest) can explain in large part the geographical variation in species epidemiology [28]. Genetically determined host factors such as red cell abnormalities, and possibly immune response genes, may also contribute to differences observed between villages [37].

The sensitivity of RDTs in this study was $28 \%$ for $P$. falciparum infections and $3 \%$ for P. vivax infections using $\mathrm{uPCR}$ as reference. The wide discrepancy in prevalence 
measured by RDT compared to uPCR in this current study is consistent with a multi-national survey, which used the same uPCR detection technique [32]. This earlier study, conducted in Cambodia, Thai-Myanmar border and Vietnam, found a Plasmodium prevalence of $4 \%$ by RDT compared to $20 \%$ by uPCR. A survey using RDT conducted in Laos in 2006-2008 [1, 2] found a $1.2 \%$ prevalence of $P$. falciparum infections-similar to the $0.9 \% P$. falciparum prevalence detected by RDT in the current study.

Several factors were associated with $P$. vivax monoinfections. Being a male was associated with higher prevalence of $P$. vivax infection than being female. The increased risk of contracting malaria for males may be explained by work-related exposure in the field and forested areas [3]. A similar gender imbalance was also observed on the Thailand-Myanmar border, in Cambodia [27] and Ethiopia [5, 38]. A history of sleeping in the forest was found to be associated with increased $P$. vivax prevalence. Forest workers have been traditionally a high-risk group for malaria in the Greater Mekong Sub-region [3, 39-43]. Control of forest malaria has proven to be highly challenging and innovative approaches will be needed to interrupt malaria transmission among forest workers.

The peak risk for Plasmodium infections in this study was in the age group 15-35 years and decreased with older age. Younger participants may have been less exposed to vectors while older participants may have developed sufficient immunity to clear infections. A similar peak prevalence in adults has been observed in past studies in Laos [44] and Cambodia [35].

\section{Conclusion}

The study found a high prevalence of asymptomatic Plasmodium infections as detected by uPCR and three times more $P$. vivax than $P$. falciparum infections in the southern Savannakhet Province. The distribution of infections was very heterogeneous, with some villages nearly free of infections while in other villages more than half of the village population was infected. The majority of $P$. falciparum strains in Thapangthong District carried markers suggesting reduced susceptibility to artemisinin derivatives. These strains are also already present in the more remote Nong District. This worrying trend has wider implications for Laos and could reverse the gains achieved by the successful control of malaria in Laos and the GMS. The rapid elimination of P. falciparum should be a top priority in Laos and the GMS before malaria there becomes untreatable. Such elimination will require targeted interventions in high prevalence villages.

\section{Authors' contributions}

KP, BA, GH, TP, LvS, NJW, AMD, PNN, and MM: study design; MI: molecular biology; GH: data management; LvS: statistics. All authors read and approved the final manuscript.

\begin{abstract}
Author details
${ }^{1}$ Microbiology Laboratory, Lao-Oxford-Mahosot Hospital-Wellcome Trust Research Unit (LOMWRU), Vientiane, Lao PDR. ${ }^{2}$ Mahidol Oxford Tropical Medicine Research Unit (MORU), Faculty of Tropical Medicine, Mahidol University, Bangkok, Thailand. ${ }^{3}$ Savannakhet Provincial Health Department, Nakhon Sawan, Savannakhet Province, Lao PDR. ${ }^{4}$ Centre for Tropical Medicine and Global Health, Nuffield Department of Clinical Medicine, University of Oxford, Oxford, United Kingdom. ${ }^{5}$ Faculty of Postgraduate Studies, University of Health Sciences, Vientiane, Lao PDR.
\end{abstract}

\section{Acknowledgements}

We would like to thank all participants in the study and the staff from the provincial hospital and Mahosot Hospital who supported the study. We thank the following people for their dedicated support which made this study possible: Mrs. Bounmy Syphachanh, Mrs. Vilayphone Phananan, Mr. Khamma, Dr. Bouasy Hongvanthong, Mrs. Kingkeo Khamkuang, Mrs. Phousavanh Sysouphanh, Mr. Bounthanom Lombuakham, Mrs. Lampathou Heuangsackda, Mr. Sounthaly Souvannasan, Dr. Phouvieng Douangdala, Dr. Lamngeun Xaygnavongsy, Mr. Chanthala Vilayhong, Mrs. Dala Keokhamhong, Jem Chalk, and Nicola James. This work was supported by and the Wellcome Trust (reference 101148/Z/13/Z) and the Bill and Melinda Gates Foundation (BMGF OPP1081420). MI was supported through Mahidol University.

\section{Competing interests}

The authors declare that they have no competing interests.

Received: 16 April 2016 Accepted: 10 May 2016

Published online: 27 May 2016

\section{References}

1. Ministry of Health PDR Laos. National strategy for malaria control and pre-elimination 2011-2015. National Report 2010.

2. Jorgensen P, Nambanya S, Gopinath D, Hongvanthong B, Luangphengsouk K, Bell D, et al. High heterogeneity in Plasmodium falciparum risk illustrates the need for detailed mapping to guide resource allocation: a new malaria risk map of the Lao People's Democratic Republic. Malar J. 2010;9:59.

3. Pongvongsa T, Ha H, Thanh L, Marchand RP, Nonaka D, Tojo B, et al. Joint malaria surveys lead towards improved cross-border cooperation between Savannakhet Province, Laos and Quang Tri province, Vietnam. Malar J. 2012;11:262.

4. Lindblade KA, Steinhardt L, Samuels A, Kachur SP, Slutsker L. The silent threat: asymptomatic parasitemia and malaria transmission. Expert Rev Anti Infect Ther. 2013;11:623-39.

5. Golassa L, Enweji N, Erko B, Aseffa A, Swedberg G. Detection of a substantial number of sub-microscopic Plasmodium falciparum infections by polymerase chain reaction: a potential threat to malaria control and diagnosis in Ethiopia. Malar J. 2013;12:352.

6. Harris I, Sharrock WW, Bain LM, Gray KA, Bobogare A, Boaz L, et al. A large proportion of asymptomatic Plasmodium infections with low and sub-microscopic parasite densities in the low transmission setting of Temotu Province, Solomon Islands: challenges for malaria diagnostics in an elimination setting. Malar J. 2010;9:254.

7. Rogier C, Commenges D, Trape JF. Evidence for an age-dependent pyrogenic threshold of Plasmodium falciparum parasitemia in highly endemic populations. Am J Trop Med Hyg. 1996;54:613-9.

8. Boudin C, Olivier M, Molez JF, Chiron JP, Ambroise-Thomas P. High human malarial infectivity to laboratory-bred Anopheles gambiae in a village in Burkina Faso. Am J Trop Med Hyg. 1993;48:700-6.

9. Coleman RE, Kumpitak C, Ponlawat A, Maneechai N, Phunkitchar V, Rachapaew N, et al. Infectivity of asymptomatic Plasmodium-infected human populations to Anopheles dirus mosquitoes in western Thailand. J Med Entomol. 2004;41:201-8.

10. Schneider P, Bousema JT, Gouagna LC, Otieno S, van de Vegte-Bolmer M, Omar SA, et al. Submicroscopic Plasmodium falciparum gametocyte densities frequently result in mosquito infection. Am J Trop Med Hyg. 2007;76:470-4 
11. Muirhead-Thomson RC. Low gametocyte thresholds of infection of Anopheles with Plasmodium falciparum; a significant factor in malaria epidemiology. BMJ. 1954;1:68-70.

12. Ashley EA, Dhorda M, Fairhurst RM, Amaratunga C, Lim P, Suon S, et al. Spread of artemisinin resistance in Plasmodium falciparum malaria. N Engl J Med. 2014;371:411-23.

13. von Seidlein $\mathrm{L}$. The failure of screening and treating as a malaria elimination strategy. PLoS Med. 2014;11:e1001595.

14. Maude RJ, Pontavornpinyo W, Saralamba S, Aguas R, Yeung S, Dondorp AM, et al. The last man standing is the most resistant: eliminating artemisinin-resistant malaria in Cambodia. Malar J. 2009:8:31.

15. Mpacm WHO. Malaria elimination strategy in the greater Mekong subregion. Geneva: World Health Organization; 2015.

16. Inkhamseng S. Improving the resilience of the agriculture sector in Lao PDR to climate change impacts. Baseline survey report in Savannakhet Province 2012. Lao People's Democratic Republic. 2012. (http://www. adaptation-undp.org/sites/default/files/downloads/baseline_savannakhet_iras_july_2012.pdf)

17. Poverty-Environment Initiative Lao PDR, UNDP. Report on economic, social and environmental costs and benefits of investments in Savannakhet Province. International Union for Conservation of Nature Lao PDR. 2011. (http://www.unpei.org/sites/default/files/e_library_documents/ Lao_Report_ESE_Costs_Benefits_Savannakhet_Province_2011.pdf).

18. Imwong M, Hanchana S, Malleret B, Renia L, Day NP, Dondorp A, et al. High-throughput ultrasensitive molecular techniques for quantifying low-density malaria parasitemias. J Clin Microbiol. 2014;52:3303-9.

19. Ariey F, Witkowski B, Amaratunga C, Beghain J, Langlois AC, Khim N, et al. A molecular marker of artemisinin-resistant Plasmodium falciparum malaria. Nature. 2014;505:50-5.

20. Manske M, Miotto O, Campino S, Auburn S, Almagro-Garcia J, Maslen G, et al. Analysis of Plasmodium falciparum diversity in natural infections by deep sequencing. Nature. 2012;487:375-9.

21. Mayxay M, Thongpraseuth V, Khanthavong M, Lindegardh $N$, Barends $M$, Keola S, et al. An open, randomized comparison of artesunate plus mefloquine vs. dihydroartemisinin-piperaquine for the treatment of uncomplicated Plasmodium falciparum malaria in the Lao People's Democratic Republic (Laos). Trop Med Int Health. 2006;11:1157-65.

22. Mayxay M, Sengvilaipaseuth $O$, Chanthongthip A, Dubot-Peres A, Rolain JM, Parola P, et al. Causes of fever in rural Southern Laos. Am J Trop Med Hyg. 2015;93:517-20

23. Mayxay M, Khanthavong M, Lindegardh N, Keola S, Barends M, Pongvongsa T, et al. Randomized comparison of chloroquine plus sulfadoxinepyrimethamine versus artesunate plus mefloquine versus artemetherlumefantrine in the treatment of uncomplicated falciparum malaria in the Lao People's Democratic Republic. Clin Infect Dis. 2004;39:1139-47.

24. Mayxay M, Khanthavong M, Chanthongthip O, Imwong M, Pongvongsa T, Hongvanthong B, et al. Efficacy of artemether-lumefantrine, the nationally-recommended artemisinin combination for the treatment of uncomplicated falciparum malaria, in southern Laos. Malar J. 2012;11:184.

25. Mayxay M, Keomany S, Khanthavong M, Souvannasing P, Stepniewska K, Khomthilath T, et al. A phase III, randomized, non-inferiority trial to assess the efficacy and safety of dihydroartemisinin-piperaquine in comparison with artesunate-mefloquine in patients with uncomplicated Plasmodium falciparum malaria in southern Laos. Am J Trop Med Hyg. 2010;83:1221-9.

26. Putaporntip C, Hongsrimuang T, Seethamchai S, Kobasa T, Limkittikul K, Cui L, et al. Differential prevalence of Plasmodium infections and cryptic Plasmodium knowlesi malaria in humans in Thailand. J Infect Dis. 2009;199:1143-50.

27. Steenkeste N, Rogers WO, Okell L, Jeanne I, Incardona S, Duval L, et al. Sub-microscopic malaria cases and mixed malaria infection in a remote area of high malaria endemicity in Rattanakiri province, Cambodia: implication for malaria elimination. Malar J. 2010:9:108.
28. Waltmann A, Darcy AW, Harris I, Koepfli C, Lodo J, Vahi V, et al. High rates of asymptomatic, sub-microscopic Plasmodium vivax infection and disappearing Plasmodium falciparum malaria in an area of low transmission in Solomon Islands. PLoS Neglect Trop Dis. 2015;9:e0003758.

29. Branch O, Casapia WM, Gamboa DV, Hernandez JN, Alava FF, Roncal N, et al. Clustered local transmission and asymptomatic Plasmodium falciparum and Plasmodium vivax malaria infections in a recently emerged, hypoendemic Peruvian Amazon community. Malar J. 2005;4:27.

30. Oliveira-Ferreira J, Lacerda MV, Brasil P, Ladislau JL, Tauil PL, Daniel-Ribeiro CT. Malaria in Brazil: an overview. Malar J. 2010;9:115.

31. WHO. World Malaria Report. Geneva, World Health Organization, 2014.

32. Imwong M, Nguyen TN, Tripura R, Peto TJ, Lee SJ, Lwin KM, et al. The epidemiology of subclinical malaria infections in South-East Asia: findings from cross-sectional surveys in Thailand-Myanmar border areas, Cambodia, and Vietnam. Malar J. 2015;14:381.

33. Garros C, Van Bortel W, Trung HD, Coosemans M, Manguin S. Review of the minimus complex of Anopheles, main malaria vector in Southeast Asia: from taxonomic issues to vector control strategies. Trop Med Int Health. 2006;11:102-14

34. Obsomer V, Defourny P, Coosemans M. The Anopheles dirus complex: spatial distribution and environmental drivers. Malar J. 2007;6:26.

35. Incardona S, Vong S, Chiv L, Lim P, Nhem S, Sem R, et al. Large-scale malaria survey in Cambodia: novel insights on species distribution and risk factors. Malar J. 2007;6:37.

36. Greenwood BM. The microepidemiology of malaria and its importance to malaria control. Trans R Soc Trop Med Hyg. 1989;83(Suppl):25-9.

37. Band G, Rockett KA, Spencer CC, Kwiatkowski DP. A novel locus of resistance to severe malaria in a region of ancient balancing selection. Nature. 2015;526:253-7.

38. Golassa L, Baliraine FN, Enweji N, Erko B, Swedberg G, Aseffa A. Microscopic and molecular evidence of the presence of asymptomatic Plasmodium falciparum and Plasmodium vivax infections in an area with low, seasonal and unstable malaria transmission in Ethiopia. BMC Infect Dis. 2015;15:310.

39. Thanh PV, Hong NV, Van Van N, Van Malderen C, Obsomer V, RosanasUrgell A, et al. Epidemiology of forest malaria in Central Vietnam: the hidden parasite reservoir. Malar J. 2015;14:86.

40. Bourée P. Malaria in forests (in French). Médecine et Santé Tropicale. 2014;24:147.

41. Thang ND, Erhart A, Speybroeck N, le Hung X, le Thuan K, Hung CT, et al. Malaria in central Vietnam: analysis of risk factors by multivariate analysis and classification tree models. Malar J. 2008;7:28.

42. Erhart A, Ngo DT, Phan VK, Ta TT, Van Overmeir C, Speybroeck N, et al. Epidemiology of forest malaria in central Vietnam: a large scale crosssectional survey. Malar J. 2005;4:58.

43. Erhart A, Thang ND, Hung NQ, le Toi $V$, le Hung $X$, Tuy TQ, et al. Forest malaria in Vietnam: a challenge for control. Am J Trop Med Hyg. 2004; $70: 110-8$

44. Toma H, Kobayashi J, Vannachone B, Arakawa T, Sato Y, Nambanya S, et al. A field study on malaria prevalence in southeastern Laos by polymerase chain reaction assay. Am J Trop Med Hyg. 2001;64:257-61.

\section{Submit your next manuscript to BioMed Central and we will help you at every step:}

- We accept pre-submission inquiries

- Our selector tool helps you to find the most relevant journal

- We provide round the clock customer support

- Convenient online submission

- Thorough peer review

- Inclusion in PubMed and all major indexing services

- Maximum visibility for your research

Submit your manuscript at www.biomedcentral.com/submit
C BioMed Central 